\title{
REFERENCIAÇÃO EM FOCO: A ELABORAÇÃO DIDÁTICA DA DESCRIÇÃO DEFINIDA EM GRAMÁTICA PEDAGÓGICA
}

\author{
Priscila Raposo Ananias* \\ Williany Miranda da Silva ${ }^{* *}$
}

\begin{abstract}
Resumo: Concebendo o estudo das estratégias de referenciação enquanto importante ferramenta no desenvolvimento das práticas de leitura e produção textual, o presente trabalho objetivou descrever e analisar a concepção de referente que subjaz à elaboração didática da descrição definida em uma gramática pedagógica do Ensino Médio e verificar as possíveis implicações desse tratamento didático-pedagógico no tocante ao ensino das práticas de leitura e escrita. Os dados analisados foram constituídos por fragmentos da exposição do conteúdo, atividades e orientações docentes dispostas em um capítulo, cujo conteúdo versava sobre pronome, extraído de um exemplar do professor de uma Gramática pedagógica destinada ao ensino médio. A análise parcial dos dados revelou que a descrição definida foi abordada enquanto mecanismo de menção ou retomada de referentes inseridos no mundo físico. Tal aspecto foi notadamente evidenciado pelo uso exclusivo da orientação espacial como critério determinante para o estudo dos pronomes demonstrativos.
\end{abstract}

Palavras-chave: Referenciação. Descrição Definida. Elaboração Didática. Gramática Pedagógica.

\begin{abstract}
Conceiving the study of the referencing strategies as an important tool for the reading practice and text production development, this research aimed at describing and analyzing the referent conception that lies under the didactic elaboration of the definite description in a high school pedagogical grammar and verifying the possible implications of this didactic-pedagogical treatment related to the teaching of reading and writing practices. The data analyzed consisted of passages of the content explanations, activities and teachers guidance presented in a chapter about pronouns of a teacher's version of the pedagogical grammar for high school. The partial analysis of the data revealed that the definite description was discussed as a mechanism for resuming or mentioning referents inserted in the physical world. This aspect was especially evidencced by the exclusive use of spatial orientation as a criterion for the study of demonstrative pronouns.

Keywords: Referencing. Definite Description. Didactic Elaboration. Pedagogical Grammar.

\footnotetext{
${ }^{*}$ Mestre em Linguagem e Ensino pela Universidade Federal de Campina Grande. Contato: prof.priscilaraposo@yahoo.com

** Professora Doutora do curso de Pós-Graduação em Linguagem e Ensino e da graduação do curso de Licenciatura plena em Letras da Universidade Federal de Campina Grande (UFCG). Contato: williany.silva@gmail.com
} 


\section{Introdução}

As atividades de leitura e escrita pressupõem a referência constante a entidades - criadas, desenvolvidas e consolidadas na e pela atividade discursiva (processos, fatos, eventos, sentimentos, entre outros) -, as quais são passíveis posteriormente de focalização, retomada e desfocalização. Tais movimentos textuais caracterizam a atividade de referenciação, que se mostra como essencial não só na construção de sentidos dos textos, como também na consolidação da dinamicidade do entrelaçamento coesivo textual.

É nesse sentido que Marcuschi (2003) define o processo de referenciação como "ação interativa, construtiva e não representacional, possivelmente componencial, que fornece pistas de acesso para a elaboração de sentidos" (p. 259). Para o autor, essas "pistas de acesso" acionam e atualizam domínios cognitivos, interagentes com as experiências socioculturais dos indivíduos, permitindo a (co)construção e negociação de significados nos textos.

Nessa acepção, a referenciação consolida-se como uma atividade potencialmente interativa, social e cognitiva, peça-chave, portanto, nas práticas de leitura e produção do texto, uma vez que a retomada e a (re) construção dos referentes contribuem efetivamente para o estabelecimento da textualidade.

À luz dessas considerações, a referência não é concebida como uma simples representação do mundo físico e extramental, conforme se postulou antigamente nos estudos de natureza lógico-semântica, ela é antes compreendida como as operações realizadas pelos sujeitos no desenvolvimento do discurso, resultando em entidades dinâmicas - objetos de discurso - as quais podem ser modificadas, desativadas, reativadas e recategorizadas nas atividades comunicativas $(\mathrm{KOCH}, 2002$; ZAMPONI, 2003; dentre outros).

Considerando a relevância de se conceber o estudo da referenciação enquanto uma importante ferramenta no desenvolvimento das práticas de leitura e produção textual, assim como com o intuito de conduzir uma compreensão do tratamento didático-pedagógico concedido a esse tema nos instrumentos que subsidiam a ação docente, esse artigo foi norteado pelo seguinte questionamento: Que concepção de referente (objeto de mundo ou objeto de discurso) subjaz a elaboração didática dos saberes acerca da descrição definida em gramática pedagógica? 
Posto isso e tendo em vista o caráter aplicado desse estudo, objetivamos: (1) descrever e analisar a concepção de referente, que subjaz à elaboração didática dos saberes acerca da descrição definida em uma gramática pedagógica do Ensino Médio e (2) verificar as possíveis implicações do tratamento concedido pela gramática à estratégia de referenciação em foco no tocante ao ensino de gramática, leitura e escrita.

Para tanto, nos valemos de dados coletados em um capítulo, cujo conteúdo versava sobre pronome, de uma gramática pedagógica de volume único (livro do professor) direcionada ao Ensino Médio.

Este estudo está organizado em quatro partes, além desta introdução: na primeira, explicitamos os pressupostos metodológicos; em seguida discutimos as concepções de referente nas perspectivas lógicosemântica e sociocognitivo-interacionista, culminando com a breve explanação das estratégias de referenciação; na terceira parte, definimos e caracterizamos a descrição definida, bem como verificamos o tratamento didático conferido a mesma pela gramática em análise e por fim, na quarta parte, tecemos as considerações finais desse artigo.

\section{Procedimentos metodológicos}

Tendo em vista que esse estudo está situado especificamente na área da Linguística Aplicada (LA) em sua vertente ligada ao ensino/ aprendizagem de Língua Materna, optamos pela abordagem qualitativa assumindo, portanto, uma postura ligada à descrição e interpretação dos dados coletados.

No que concerne ao nosso objeto de análise, a gramática pedagógica está sendo considerada nesse estudo como um dos instrumentos didáticos, que subsidia as aulas de Língua Portuguesa. Nesse sentido, estamos a denominando enquanto compêndio didático, que objetiva expor sistematicamente todos os conteúdos curriculares mais relevantes no tocante ao estudo dos fenômenos linguístico-gramaticais da disciplina de Língua Portuguesa em um determinado nível de ensino, que no caso do nosso estudo, está situado no nível médio. Diferentemente, do manual didático, que é organizado basicamente como um roteiro de atividades de ensino/ aprendizagem a ser seguido por série, a gramática pedagógica - apesar da seleção e a ordenação dos conteúdos, a cada série e a cada aula (PNLEM, 2004) ${ }^{1}$. 
Percebemos que esse instrumento é elaborado paralelamente aos manuais didáticos ou livros didáticos, uma vez que são confeccionados com a clara intenção de adoção em sala de aula, organizam-se geralmente com a apresentação de exercícios após a exposição dos conteúdos gramaticais e "aparentemente" são menos tradicionais do que as gramáticas teóricas de referência (NEVES, 2003).

Os dados constitutivos desse estudo foram provenientes do capítulo 14, intitulado Pronome - da Gramática: palavra, frase e texto (NICOLA, 2009) de volume único, destinada ao Ensino Médio. O exemplar utilizado foi o livro do professor, haja vista que as orientações teóricometodológicas também foram objeto de análise nesse estudo, uma vez que essas direcionam, determinam e influencia substancialmente a abordagem dos conteúdos a serem mobilizados pelo professor em sala de aula.

No decorrer da análise, confrontamos dados advindos da explicitação teórica da descrição definida, suas respectivas atividades e as orientações teórico-metodológicas destinadas aos docentes. Sendo assim, a exibição dos dados analisados seguiu uma sistematização padronizada, na qual todos os fragmentos de análise foram designados "Exemplos" e cada exemplo foi codificado conforme sua natureza: ET para os fragmentos relativos à Exposição Teórica; AT para as atividades e OP para os fragmentos relativos às orientações para os professores. Tais códigos foram seguidos da numeração do capítulo e sua respectiva página, por exemplo, o código AT04-60 corresponde respectivamente à atividade (AT), capítulo quatro (04) e página sessenta (60).

\section{Compreendendo a trajetória do referente à referenciação e a noção de elaboração didática}

A referência tem sido objeto de estudo em diferentes domínios de conhecimentos, dentre os quais podemos destacar a filosofia, a lógica, a semântica, a linguística, a cognição, entre outras ciências. Interessa a esse trabalho focalizar duas tendências predominantes na maneira de se tratar e se conceber a referência no interior na Línguística Textual (LT): a

${ }^{1} \overline{\text { Catálogo do }}$ Programa Nacional do Livro Didático para o Ensino Médio. perspectiva lógico-semântica e a perspectiva sociocognitivo-interacionista.

A primeira perspectiva postula a existência de uma relação direta e biunívoca entre linguagem e mundo. Nessa concepção, a referência é 
apontada como uma forma extensional de representar a realidade objetiva do mundo, com isso, os referentes são concebidos enquanto objetos do mundo físico e extramental. Sob este prisma, a atividade de referenciação é reduzida ou limitada ao estabelecimento de elos anafóricos entre uma dada forma linguística e seu antecedente na sentença.

Para Souza (2010), tal concepção abarca uma teoria de referência na qual os termos semânticos, bem como "os enunciados em que os referentes se inserem têm de ser submetidos a condições de verdade e não a condições de uso" (p.41-42). Percebe-se que os mecanismos referenciais eram focalizados sob uma ótica abstrata enquanto elementos portadores de propriedades lógicas, as quais deveriam ser desvendadas, apreendidas e, em seguida, transpostas para a produção de textos orais e escritos, ou seja, há uma acentuada inversão do caminho nos estudos lingüísticos, cujo uso é apontado como ponto de chegada, não como ponto de partida, conforme se postula nas práticas de análise lingüística.

Ainda de acordo com a autora, tal concepção pode ser denominada especular, uma vez que defende que a função referencial reflete uma correspondência direta entre as palavras e as coisas, sustentando uma visão autônoma de mundo, na qual as coisas existem independentemente do sujeito se referir a elas e, nesse entremeio, a representação linguística também se ajusta a esse mundo real.

A perspectiva sociocognitivo-interacionista, por sua vez, foi edificada sob o ponto de vista de que a atividade referencial não pressupõe uma correspondência direta e estável entre as entidades do mundo e da língua, bem como sob a percepção de que "nossa maneira de ver e dizer o real não coincide com o real" (KOCH, 2004, p.55). Ao conceber a linguagem como atividade eminentemente interativa e sociocognitiva, essa perspectiva aponta a referência como a base da significação e os referentes, por sua vez, como objetos de discurso, ou seja, entidades criadas, desenvolvidas e consolidadas na e pela atividade discursiva. Essa perspectiva diverge da anterior, sobretudo, por defender o uso em detrimento da verdade e da lógica lingüística, isto é, ela inverte o caminho nos estudos sobre referenciação, estabelecendo o uso como ponto de partida a distinção entre objetos de mundo e objetos de discurso. Tal distinção, para Souza (2010), representa literalmente um divisor de águas entre duas concepções teóricas em torno da referenciação:

Na perspectiva ostensiva, especular, a noção de referente implica a existência de uma entidade real no mundo, que, 
transposta ou instalada no cotexto, remete de novo para essa entidade de existência real como numa operação de refração. $\mathrm{Na}$ perspectiva sociointerativa, o referente não pressupõe uma existência extralingüística fora da atividade cognitiva e interativa: o referente é construído no interior do e através do próprio discurso, recortado pela dimensão perceptivocognitiva e subjetiva que criamos no universo textual (SOUZA, 2010, p.43-44, grifo da autora)

É possível depreendermos nas palavras da autora que a referenciação é acima de tudo uma atividade cooperativa, cujos sujeitos envolvidos pertencem ou compartilham a mesma comunidade linguística e epistêmica e, por intermédio de práticas discursivas e cognitivamente situadas, constroem "versões públicas do mundo" (MONDADA e DUBOIS, 2003, p.17).

Segundo essas autoras, os objetos de discurso não são preexistentes e possuem uma instabilidade constitutiva, uma vez que são elaborados no interior das atividades comunicativas e sofrem transformações provenientes do contexto em que estão instaurados. É nesse sentido que o referente é fabricado pela prática social e torna-se fruto da percepção cultural, haja vista que a língua não existe fora dos sujeitos sociais e dos eventos discursivos.

Ao abandonarem o questionamento acerca da relação entre as palavras e as coisas e a pressuposição da estabilidade entre as entidades no mundo e na língua, Mondada e Dubois (op. cit.) propõem a investigação da instabilidade constitutiva das categorias cognitivas e linguísticas e seus processos de estabilização, buscando compreender de que maneira as atividades humanas, cognitivas e linguísticas, estruturam e conferem sentido ao mundo. Tal mudança implica uma visão dinâmica que engloba não só o sujeito físico, como também o sujeito sócio-cognitivo "mediante uma reação indireta entre os discursos e o mundo" (p. 20).

Com isso, a referenciação é encarada pelos autores, assim como no presente estudo, enquanto processo que se desenvolve nas interações sociais e individuais com o mundo e com os outros. Torna-se relevante, portanto, a descrição dos procedimentos linguísticos e sócio-cognitivos pelos quais os atores sociais se referem uns aos outros. Esses procedimentos se instauram como "processo de ajustamento das palavras que não se faz diretamente em relação ao referente dentro do mundo, mas no quadro contextual, a fim de construir objetos de discurso ao curso do próprio processo de referenciação" (MONDADA e DUBOIS, 2003, p. 33). 
À luz dessas considerações, conclui-se que os objetos de discurso emergem ao longo do ato de enunciação e que sua instabilidade está ligada não só ao fator intersubjetivo das atividades cognitivas, como também às variações de ordem contextual. Além disso, merece destaque o fato de esses objetos de discurso serem co-construídos, pois, uma vez introduzidos no discurso, eles sofrem transformação e não pertencem mais unicamente àquele que produziu o enunciado, pois passam a ser ordenados coletivamente, independentemente das intenções individuais.

O processo ou a atividade discursiva de introduzir e (re)construir objetos de discurso denomina-se referenciação. Esse processo se instaura no interior do próprio discurso, de acordo com a percepção de mundo, atitudes, conhecimentos e propósitos comunicativos dos interactantes. No desenvolvimento dessa atividade discursiva Koch e Elias (2006) enfatizam que

\begin{abstract}
Osujeito, por ocasião da interação verbal, opera sobreomaterial linguístico que tem à sua disposição e procede a escolhas significativas para representar estados de coisas, de modo condizente com a sua proposta de sentido. Isto é, as formas de referenciação são escolhas do sujeito em interação com outros sujeitos, em função de um querer-dizer. Os objetos de discurso não se confundem com a realidade extralingüística, eles a (re) constroem no próprio processo de interação (KOCH e ELIAS, 2006, p.124)
\end{abstract}

Tais operações referenciais realizadas pelos sujeitos no decorrer da interação são bastante complexas por envolverem a mobilização do saber construído linguisticamente no interior do próprio texto e os conteúdos inferenciais que podem ser calculados a partir dos elementos nele presentes ${ }^{2}$. Além disso, sofrem intervenção dos saberes, opiniões, crenças e juízos mobilizados na interação autor- texto - leitor. De acordo com Koch e Elias

${ }^{2}$ As inferências são possíveis devido aos conhecimentos lexicais, enciclopédicos e culturais adquiridos pelos sujeitos durante a sua vivência em sociedade.

(2006), quando referentes são retomados no decorrer do texto ou servem de base para a introdução de novos referentes é estabelecida a progressão referencial. A respeito disso, Marcuschi (2000) acrescenta

A idéia de continuidade dos referentes, que a referenciação suscita, no caso da construção da progressão referencial, não implica necessariamente retomada dos mesmos referentes, 
nem sua manutenção completa, pois o encadeamento referencial organiza-se num sistema de correlações como uma rede multidimensional. Assim, não é uma condição necessária da textualidade a ligação linear de elementos linguísticos, já que a textualização se dá num processo de multilinearização (p.191, grifos do autor)

Percebe-se claramente nas palavras do autor que a construção da progressão referencial demanda, sobretudo, o processamento de atividades inferenciais não automáticas e de caráter cognitivo-pragmático. Fica claro que as formas de construção referencial não se fundam exclusivamente na correferenciação ${ }^{3}$, uma vez que tanto o processo de construção e retomadas de referentes quanto a compreensão destes pelo interlocutor qualificam-se como atividades inferenciais, cognitivas e interativo-discursivas.

Koch (2004) destaca na operação discursiva de referenciação a existência de três estratégias: a introdução (ativação/construção), a retomada (manutenção/reativação) e a desfocalização (de-ativação).

A primeira estratégia ocorre quando um referente textual ainda não mencionado é inserido no texto, preenchendo assim um "endereço" cognitivo, desse modo, tal expressão linguística posta em foco tornase saliente no modelo textual. Koch e Elias (2006; 2010) apontam dois tipos de introdução de referentes no modelo textual: a ativação 'ancorada' e 'não-ancorada'. A introdução referencial será 'não ancorada' quando o produtor introduz no texto um objeto de discurso totalmente novo e 'ancorada' quando, em virtude da associação entre elementos presentes no cotexto ou contexto sociocognitivo, um novo objeto de discurso é introduzido como dado, portanto, percebe-se que as introduções ancoradas fundam-se por meio de relações eminentemente associativas e inferenciais.

3 Para Apothéloz (2003) existe correferência quando duas expressões designam no discurso o mesmo referente. Tal operação pode ocorrer através de repetição, sinônimo ou designação alternativa e elipse; implica identidade material absoluta, mas não sinonímia lexical absoluta.

Incluem-se nesse tipo de introdução as anáforas associativas e indiretas, as nominalizações, encapsulamentos e rotulações.

Já a segunda estratégia acontece quando um referente textual já introduzido é novamente ativado por meio de uma forma referencial, conservando a focalização do objeto de discurso. Tal operação responsável pela manutenção em foco de objetos previamente introduzidos no modelo 
discursivo e pela origem das cadeias referenciais ou coesivas. Tal operação se realiza tanto por intermédio de recursos gramaticais (pronominalização, elipses, numerais, entre outros) quanto por recursos lexicais (repetição, sinônimos, hiperônimos, expressões nominais definidas, etc.).

A terceira estratégia ocorre quando se introduz um novo objeto de discurso focalizando-o no modelo textual. E em seguida, esse objeto é retirado do foco, permanecendo em estado de ativação parcial (stand by), e, ao mesmo tempo, disponível para utilização imediata conforme necessidade do produtor. Vejamos no tópico 4, a seguir, em qual dessas estratégias a descrição definida está situada e de que modo, ela é abordada pela gramática em análise.

\subsection{A descrição definida}

Koch e Elias (2006) inserem as expressões ou descrições nominais definidas e indefinidas como um tipo de estratégia referencial portadora de função remissiva na construção de sentidos dos textos.

As descrições definidas são constituídas pela junção de um determinante definido (artigo definido ou pronome demonstrativo) e um nome. Esse tipo de estratégia opera uma ativação - dentre os conhecimentos pressupostos como partilhados com os interlocutores - de características de um determinado referente que o locutor procura destacar segundo suas intenções.

Com isso, percebemos que as descrições nominais definidas evocam não só conhecimentos linguísticos como também o conhecimento de mundo partilhado entre os interlocutores. A utilização desse mecanismo pelo produtor ocorre pelo fato deste pressupor que o seu interlocutor possui plenas condições de reconhecer na sua produção discursiva o referente da descrição a que ele se refere, em contrapartida, da parte do interlocutor, o uso da descrição definida por aquele, possibilita a diferenciação do referente mencionado de outros presentes no universo discursivo.

Ao ativar traços do objeto de discurso partilhados entre os interlocutores, a descrição definida ergue-se como uma estratégia que possui uma função predicativa, uma vez que sempre implica numa escolha dentre uma multiplicidade de formas de caracterizar um determinado referente. Logo, concluímos que essa estratégia consolida-se como uma importante ferramenta de manifestação de avaliações, "opiniões, crenças e atitudes do produtor do texto, auxiliando-o na construção de sentido" 
(Koch e Elias, op. cit., p.133). Além disso, as descrições definidas também possuem função informativa, pois podem revelar, por parte do produtor, a intenção de explicitar características, propósitos ou fatos em relação ao referente, que poderiam ser desconhecidos pelo interlocutor.

\subsection{O processo de elaboração didática dos saberes}

O termo "elaboração didática dos saberes" é proposto por Halté (2008) em substituição ao termo "transposição didática", visando extinguir a limitação e problemática desencadeada por esse, uma vez que a palavra "transposição" carrega consigo a ideia de "extrair algo de um lugar e colocar em outro", resultando numa noção de didatização de saberes restrita, cuja primazia recai na supervalorização e no aplicacionismo puro dos saberes científicos no ensino.

Esse autor, tal como Petitjean (2008), defende uma concepção mais ampla e solidária entre os saberes ao afirmar que todo saber teórico quando inserido em um programa de ensino sofre inevitavelmente rupturas, deslocamentos e transformações. Tais mudanças são essenciais devido à condição e necessidade de diálogo entre os saberes a serem ensinados e as práticas sociais de referência, uma vez que aqueles devem englobar e refratar essas práticas, a partir dos três pólos do triângulo didático: o saber, o professor e o aluno.

Além disso, fatores históricos, culturais, psicológicos, políticos, entre outros, não podem ser desconsiderados e ficar a margem desse processo, uma vez que eles incidem e interferem diretamente não só na elaboração didática dos saberes como perpassam todo o processo de ensinoaprendizagem (CRISTOVÃO, 2004).

Os objetos de ensino de uma disciplina como língua portuguesa são naturalmente objetos complexos, cuja abordagem implica uma conjuntura de saberes heterogêneos, no sentido de ampliar a competência comunicativa dos discentes. Nesse contexto, Petitjean (op.cit.) ressalta que a confecção dos manuais de ensino - dentre os quais fazem parte as gramáticas pedagógicas - implica vários atos de elaboração didática, tais como: seleção das noções a serem ensinadas; integração dessas noções entre si; modos de definição e grau de formulação das mesmas; tipos de progressão; modos de programação dos saberes (escolha dos textos e seus suportes, tipos de questionamentos, exercícios, modos de aprendizagem).

Depreende-se disso que a elaboração didática de saberes - 
subjacente tanto aos materiais didático-pedagógicos quanto à prática de ensino em sala de aula - é composta pela mobilização, solidarização, mesclagem e sincretização de saberes plurais e oriundos de fontes sociais diversas. Tal processo de didatização é inevitável por se fazer presente em todas as etapas relacionadas ao ensino e a aprendizagem, aspecto que o torna passível de análises e explicações, uma vez que podemos identificar sua incidência e mecanismos mobilizados em relação ao ensino de um determinado conteúdo. E é justamente isso que pretendemos compreender ao focarmos nossa investigação na didatização da descrição definida enquanto estratégia de referenciação.

\section{A elaboração didática da descrição definida pela gramática}

O exemplo 1, que segue, ilustra a abordagem da descrição definida em uma atividade presente na gramática em análise:

\section{Exemplo 1}

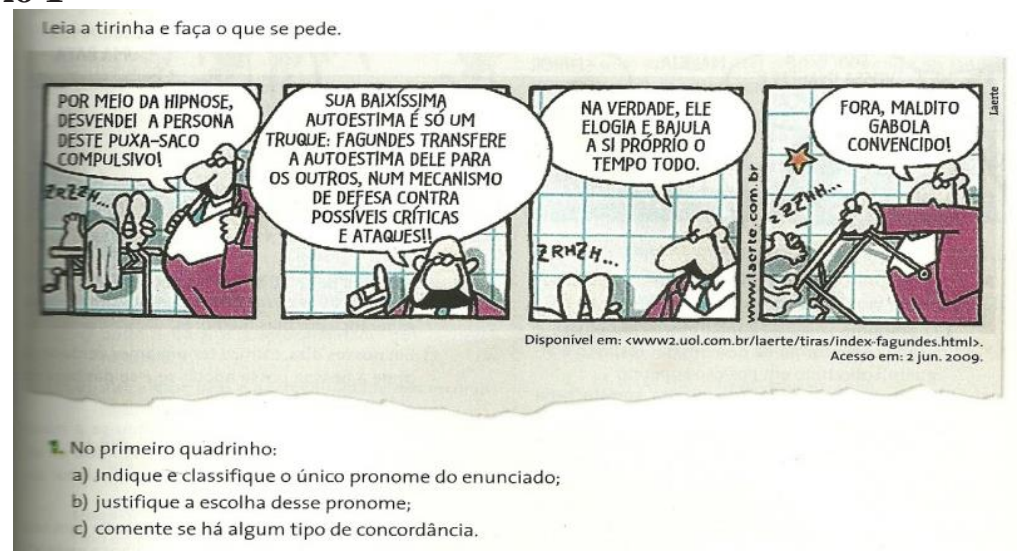

AT14 - 253

O comando da primeira questão do exemplo 1 solicita do aluno habilidades ligadas à identificação do pronome "deste", sua posterior classificação (nomenclatura), seguida da constatação da motivação dessa escolha e, por fim, o tipo de concordância suscitada pela mesma.

Todos os comandos da atividade estão focados apenas no pronome demonstrativo, ignorando-se tanto sua função discursiva decorrente da junção com o sintagma nominal "puxa-saco" (primeiro quadrinho), quanto a variedade de pronomes apresentada na tira. Este aspecto revela de antemão uma perspectiva reducionista na forma de tratar os fenômenos em 
uso, uma vez que há o abandono da função exercida pela descrição definida em detrimento da focalização e exploração do pronome "desta", bem como sua sobreposição em detrimento da abordagem da riqueza de sentidos e da funcionalidade dos outros tipos como o "sua" e "dele" (segundo quadrinho), e "ele" e "si" (terceiro quadrinho).

Além disso, as solicitações presentes nos itens "a" e "c" são bastante familiares ao que normalmente se encontra em gramáticas prescritivas arraigadas à tradição, cuja prioridade é classificar e identificar os fenômenos linguísticos, primando pela formação de analistas da língua em detrimento do desenvolvimento de competências nos seus usuários (PERINI, 1995). Subjaz às questões dessa natureza um ensino de língua apoiado em métodos transmissivos e de memorização de regras e nomenclaturas, que desconsidera os objetivos primordiais do ensino de Língua Portuguesa, ligados à formação de competências e habilidades linguísticas nos alunos.

O foco na classificação (item "a") e no tipo de concordância (item “c') ilustra a preocupação com o domínio da nomenclatura no tocante à tipologia pronominal e com as regras de concordância, que se estabelecem na utilização de uma forma de pronome variável. À luz dessa concepção, o ensino de língua torna-se restrito - a definições, classificações e rotulações das unidades estruturais da língua - e sujeito a padrões determinados pela escrita, isto é, um ensino "sobre a língua" (vista como produto acabado e um pretexto para o trabalho gramatical de maneira inflexível, fragmentada, prescritiva e descontextualizada). Sendo assim, saber gramática equivale a conhecer e dominar normas linguísticas de modo operacional (FRANCHI, 2006).

A adoção desse método transmissivo e de memorização pelos materiais didáticos culmina não só no abandono dos aspectos discursivos, cognitivos e semânticos envoltos no uso da língua, como também resulta no apagamento do objetivo primordial de estudá-la. Tal objetivo, de acordo com Perini (1995), encontra-se na condução dos alunos à leitura e produção escrita razoáveis, entendendo-se tais práticas como pré-requisitos essenciais para o estudo da gramática. Ou seja, podemos deduzir que antes de tudo é preciso que se saiba ler bem, para que se desenvolva a língua padrão. Esse ponto de partida constitui-se o caminho inverso do que o ensino tradicional apregoa.

O item "b" aparentemente direciona o aluno para uma reflexão em torno de uma justificativa para o uso do pronome demonstrativo na descrição definida "Deste puxa-saco compulsivo", o que configuraria 
uma perspectiva de ensino da referenciação e de gramática diferenciada da adotada nos itens anteriores, uma vez que o foco é para as possíveis motivações que determinaram o uso desse pronome e não de outros. Vejamos de que maneira a exposição teórica do conteúdo sobre pronome demonstrativo - que subsidia a atividade disposta no exemplo 1- está disposta na gramática:

\section{Exemplo 2}

\section{Pronome demonstrativo}

Pronome demonstrativo é aquele que indica a posição de um ser em relação às pessoas do discurso, situando-o no tempo ou no espaço. Como os outros pronomes, o demonstrativo também pode ser flexionado em gênero, número e pessoa. Apenas uma novidade: para cada uma das pessoas do discurso, há um demonstrativo invariável, uma forma neutra.

Considerando o que indica cada demonstrativo, podemos montar o seguinte quadro:

DEMONSTRATIVOS

\begin{tabular}{l|l|l|l}
\hline \multicolumn{1}{c|}{ noção espacial } & \multicolumn{1}{c}{ noção temporal } & formas variáveis & formas invariáveis \\
\hline $\begin{array}{l}\text { proximidade } \\
\text { da pessoa que fala }\end{array}$ & presente & $\begin{array}{l}\text { este, esta } \\
\text { estes, estas }\end{array}$ & isto \\
$\begin{array}{l}\text { proximidade } \\
\text { da pessoa com quem } \\
\text { se fala ou coisa pouco } \\
\text { distante }\end{array}$ & $\begin{array}{l}\text { passado ou } \\
\text { futuro } \\
\text { próximos }\end{array}$ & esses, essas & isso \\
$\begin{array}{l}\text { proximidade } \\
\text { da pessoa de quem se fala } \\
\text { ou coisa muito distante }\end{array}$ & $\begin{array}{l}\text { passado } \\
\text { remoto }\end{array}$ & $\begin{array}{l}\text { aquele, aquela } \\
\text { aqueles, aquelas }\end{array}$ & aquilo \\
\hline
\end{tabular}

\section{ET14 - 246/247}

O exemplo 2 expõe uma definição de "Pronome demonstrativo" e uma tabela, classificando o pronome "este" como demonstrativo e variável (na atividade em questão o pronome aparece aglutinado com a preposição de, compondo o "deste" indicando uma noção de proximidade da pessoa de quem se fala). Constata-se, pois, com a escolha do pronome demonstrativo, a noção espacial (proximidade/distanciamento) das pessoas do discurso, situando o objeto de discurso nas noções de tempo e localização. Para essa gramática, a principal função desse tipo de pronome é revelar a posição espacial de elementos presentes no contexto ou no cotexto da cena enunciativa. Tal afirmação pode ser comprovada na expectativa de resposta da atividade sugerida nas orientações direcionadas ao professor (OP), explicitadas no exemplo 3 : 


\title{
Exemplo 3
}

\begin{abstract}
1. a) este: pronome demonstrativo
b) O pronome este indica a proximidade de seu referente (o personagem Fagundes, puxa-saco compulsivo) da pessoa que fala (o médico).

c) O pronome demonstrativo este é variável e faz concordância com seu referente - o substantivo puxa-saco que, embora não manifeste a categoria gramatical de gênero, faz referência a Fagundes, masculino singular.
\end{abstract}

OP - 30

No exemplo 3, em especial na expectativa de resposta do item b, confirma-se a ênfase na noção espacial do pronome demonstrativo, cuja sugestão de resposta limita a motivação de uso. Nesse sentido, a pergunta "justifique a escolha desse pronome" (exemplo 1), e a resposta esperada "o pronome este indica a proximidade ..." (item b, exemplo 2) caminham em perspectivas diferentes, haja vista que o item proposto "supostamente" encaminha o aluno para uma reflexão em torno do uso e da escolha linguística (análise linguística), porém a resposta sugerida na OP, como reflexo da exposição teórica, limita o uso do demonstrativo às normas presentes em gramáticas prescritivas (regras de quando se usa os demonstrativos "esse", "este" ou "aquele" através do critério espacial, no qual o referente se encontra).

Assim, a estratégia de referenciação focalizada na atividade em questão - a descrição definida - é encarada sob uma perspectiva limitada do referente, postulando uma relação direta e biunívoca entre linguagem e mundo. Nessa concepção, a referenciação é apontada como uma forma extensional de representar a realidade objetiva do mundo (MONDADA e DUBOIS, 2003), por isso a gramática aponta a noção espacial como critério determinante no uso do pronome demonstrativo. É nesse sentido que se justifica o tipo de abordagem dada à descrição definida na atividade, na exposição teórica e nas orientações direcionadas ao docente pela gramática.

Vista de uma perspectiva discursiva de referenciação, enquanto mecanismo de (re)construção de objetos de discurso, a descrição definida em destaque na atividade do exemplo 1 - "Deste puxa-saco compulsivo" opera a ativação de características (qualificação) pretendidas pelo produtor do discurso no quadrinho, exercendo uma função predicativa acerca do referente em destaque: Fagundes (referente recuperado tanto na situação extralinguística da cena enunciativa no primeiro quadrinho - desenho do 
personagem dormindo-, quanto cataforicamente no cotexto do segundo balão em "Sua baixíssima autoestima é só um truque: Fagundes transfere...".

Sob este enfoque, é possível constatar a função argumentativa dessa estratégia de referenciação, que se materializa na manifestação de avaliação, opinião e atitudes do produtor do texto ( $\mathrm{KOCH}, 2004)$, demarcando uma escolha intencional, dentre uma multiplicidade de formas de caracterizar um determinado referente, durante a expressão de um ponto de vista. Uma abordagem nesse sentido caracterizaria uma atividade de análise linguística em função dos efeitos de sentido ocasionados pelo uso (escolha) da expressão referencial em destaque, contribuindo, assim, para o aperfeiçoamento das habilidades de leitura e escrita.

\section{Considerações finais}

Tendo em vista que esse estudo se encontra numa fase inicial, a análise parcial dos dados permitiu constatar que a descrição definida, quando composta pela junção de pronome demonstrativo e nome, é concebida pela gramática em questão como mecanismo de menção ou retomada de referentes inseridos no mundo físico ou extramental. Esse aspecto é notadamente comprovado pelo uso da orientação espacial (proximidade ou distância do referente em relação às pessoas do discurso) como critério determinante para o estudo dos pronomes demonstrativos.

À luz dessas constatações, percebe-se que a referenciação não é abordada sob uma ótica dinâmica, como atividade potencialmente interativa, social e cognitiva, uma vez que a abordagem do fenômeno permanece no nível da identificação e classificação do seu aspecto linguístico-gramatical, relegando a segundo plano o seu funcionamento discursivo. Em decorrência disso, a referenciação passa a ser comumente encarada como atividade eminentemente coesiva, cuja função não ultrapassa o mero exercício de retomada e manutenção referencial por intermédio de processos anafóricos e catafóricos, cuja função encerra na identificação, correferenciação e articulação das partes de um texto promovendo a sua progressão.

Tal abordagem atesta a fragmentação entre o ensino de língua e gramática, de um lado, e as práticas comunicativas com a linguagem, de outro. Essa polaridade se reflete visivelmente em sala de aula, sobretudo, na dificuldade demonstrada pelos discentes no tocante à transposição e mobilização dos conhecimentos adquiridos nas aulas que versam sobre os tópicos gramaticais para a produção escrita. Embora, esses mesmos alunos, 
geralmente, consigam se sair bem nas provas que cobram os conteúdos gramaticais descontextualizados. Portanto, talvez o problema não esteja nos alunos, mas no modo como os conteúdos são didatizados e abordados, tanto pelos materiais didáticos, quanto em sala de aula, dada a ausência de sistematização e articulação coerente com as práticas de leitura e escrita.

\section{Referências}

APOTHÉLOZ, D. Papel e funcionamento da anáfora da dinâmica textual. In: CAVAlCANTE, M. M.; RODRIGUES, B. B.; CIUllA, A. (Orgs.). Referenciação. São Paulo: Contexto, 2003. (Coleção Clássicos em Linguística). p.53-84.

BRASIL, Secretaria de Educação Média e Tecnológica. Catálogo do Programa Nacional do Livro Didático para o Ensino Médio: PNLEM/2005. Lingua Portuguesa. Brasília: MEC, SEMTEC, FNDE, 2004. 88 p.

CRISTOVÃO, V. L. L. A relação entre teoria e prática no desenvolvimento do professor. In: MAGALHÃES, M. C. C. (Org.). A formação do professor como um profissional crítico: Linguagem e reflexão. Campinas, SP: Mercado de Letras, 2004. (As faces da Linguística aplicada). p. 251-266.

HALTÉ, J. O espaço didático e a transposição. In: Fórum Lingüístico.

Tradução de: Ana Paula Guedes (Universidade Estadual de Maringá UEM) e Zélia Anita Viviani (Universidade Federal de Santa Catarina UFSC). Vol.5, n². Florianópolis, jul/dez., 2008. p.117-139.

KOCH, I. V. Desvendando os segredos do texto. São Paulo: Cortez Editora. 2002.

. Introdução à Linguística Textual: trajetória e grandes temas. São Paulo: Martins Fontes, 2004.

KOCH, I. V.; ELIAS, V. M. Ler e compreender: os sentidos do texto. São Paulo: Contexto, 2006.

. Escrita e progressão referencial. In: Ler e escrever: estratégias de produção. 2. ed. São Paulo: Contextọ ${ }_{58}$ 2010. p.131-157. 
MARCUSCHI, L. A. Referenciação e cognição: o caso da anáfora sem antecedente. In: PRETI, D. (Org.). Fala e escrita em questão. São Paulo: Humanitas/ FFLCH/USP, 2000. p.191-240.

- Atividades de referenciação, inferenciação e categorização na produção de sentido. In: FELTES, H.P. de M. (Org.). Produção de sentido: estudos transdisciplinares. São Paulo: Annablume; Porto Alegre: Nova Prova; Caxias do Sul: Educs, 2003. p.234-261.

MONDADA, L.; DUBOIS, D. Construção dos objetos de discurso e categorização: uma abordagem dos processos de referenciação. In: CAVAlCANTE, M. M.; RODRIGUES, B. B.; CIUlla, A. (Orgs.). Referenciação. São Paulo: Contexto, 2003. (Coleção Clássicos em Linguística). p. 17-52.

NEVES, M. H. de M. A gramática escolar. In: Gramática na escola. 7.ed. São Paulo: Contexto, 2003. p. 49-64.

NICOLA, J. de . Gramática: palavra, frase e texto. São Paulo: Scipione, 2009.

PERINI, M. A. Gramática descritiva do português. São Paulo: Ática, 1995.

PETITJEAN, A. Importância e limites da noção de transposição didática para o ensino do francês. In: Fórum Lingüístico. Tradução de: Ana Paula

Guedes (Universidade Estadual de Maringá - UEM) e Zélia Anita Viviani (Universidade Federal de Santa Catarina - UFSC). Vol.5, n². Florianópolis, jul/ dez., 2008. p. 83-116. Disponível em; < http://www.periodicos.ufsc.br/ index.php/forum/article/view/10805/11032> Acesso em: 12 ago. 2011.

SOUZA, C. N, R. de. Cadeias do texto: construindo sentidos. São Paulo: Parábola Editorial, 2010.

ZAMPONI, G. Processos de referenciação: anáforas associativas e nominalizações. 2003. 255 f. Tese (Doutorado em Lingüística). Universidade Estadual de Campinas, Campinas, 2003. 
Recebido em: agosto de 2012.

Aprovado em: novembro de 2012. 